\title{
A Case of Pandemic 2009 H1N1 Influenza A Manifestation as Apical Ballooning Syndrome
}

\author{
Se Yoon Park, Eun Jung Lee, Duk Won Bang, Tae Hyong Kim, Yang Ki Kim, Jin Wook Chung, Min Su Hyon
}

Department of Internal Medicine, Soonchunhyang University Seoul Hospital, Soonchunhyang University College of Medicine, Seoul, Korea

Critical ill patients with pandemic 2009 H1N1 influenza A are associated with mortality, including cardiovascular, respiratory and renal dysfunction. Understanding of risk factor and clinical manifestation that suggest a higher mortality can recognize high risk patients earlier. There are many reports for severe acute respiratory distress syndrome, multiple organ failure and renal failure with pandemic 2009 H1N1 influenza A. But cardiovascular disease with pandemic $2009 \mathrm{H} 1 \mathrm{~N} 1$ influenza A remains unknown. This is the report of pandemic $2009 \mathrm{H} 1 \mathrm{~N} 1$ influenza A association with apical balloning syndrome.

Keywords: Apical ballooning syndrome; Pandemic 2009 H1N1 influenza A; Pro-brain natriuretic peptide

\section{INTRODUCTION}

Current strategies for seasonal or pandemic influenza control are focused on better evaluation of complication risk, usually related with ages. Although most age at risk, usually more than 65 years of age or less than 5 years of age, are associated with influenza-associated mortalities, illness needed to be hospitalized are cardiovascular and respiratory complications other than pneumonia [1]. But relatively little is recognized as a risk factor of non-ischemic cardiovascular complications related to influenza, such as myocarditis or cardiomyopathy which usually develop without predictable causes, moreover, those of pandemic $2009 \mathrm{H} 1 \mathrm{~N} 1$ influenza $A$ is yet not well known at all. We present an experience of acute pulmonary edema associated with apical ballooning syndrome followed by pandemic $2009 \mathrm{H} 1 \mathrm{~N} 1$ influenza A.

\section{CASE REPORT}

A 78-year-old man presented to a private clinic in Seoul with aggravated dyspnea and orthopnea, 3 days after developing a fever and dyspnea. A real time polymerase chain reaction test confirmed pandemic 2009 H1N1 influenza A and he was prescribed oseltamivir. After taking only one tablet, dyspnea was rapidly aggravated and he was transferred to our hospital. He has been treated for asthma and hypertension for 15 years.

The patient's body temperature was $38.1^{\circ} \mathrm{C}$, blood pressure $150 /$ $90 \mathrm{mmHg}$, pulse rate 140 beats per minute and respiratory rate 32 beats per minute. Rales and expiratory wheezing were heard through the whole lung fields. A chest X-ray showed bilateral pulmonary edema and congestion (Fig. 1A). Electrocardiography (ECG) showed atrial fibrillation with rapid ventricular response. Digoxin $(0.5$ $\mathrm{mg}$ ) was infused intravenously to control the heart rate. Blood gas analysis showed hypoxemia $\left(\mathrm{PaO}_{2} 53 \mathrm{mmHg}, \mathrm{SaO} 2\right.$ 85\%). Ventolin nebulizer was applied. One hour later, he developed respiratory failure and was intubated and ventilated mechanically. His clinical diagnosis was pandemic 2009 H1N1 influenza A infection with secondary pneumonia and acute respiratory distress syndrome. Oseltamivir and antibiotics were administered promptly.

The next day, the pattern on the chest X-ray showed marked increased pulmonary vascularity consistent with pulmonary edema (Fig. 1B). ECG showed sinus tachycardia. So pro B-type natriuretic peptide (proBNP) and cardiac enzymes (CK-MB and troponin T)
Correspondence to: Duk Won Bang

Devision of Cardiology, Department of Internal Medicine, Soonchunhyang University Seoul Hospital, Soonchunhyang University College of Medicine, 22 Daesagwan-gil, Yongsan-gu, Seoul 140-743, Korea

Tel: +82-2-709-9345, Fax:+82-2-792-5812, E-mail: schbdw@schmc.ac.kr

Received: Mar 17, 2011 / Accepted after revision: Jun 14, 2011
(C) 2011 Soonchunhyang Medical Research Institute This is an Open Access article distributed under the terms of the Creative Commons Attribution Non-Commercial License (http://creativecommons.org/licenses/by-nc/3.0/). 

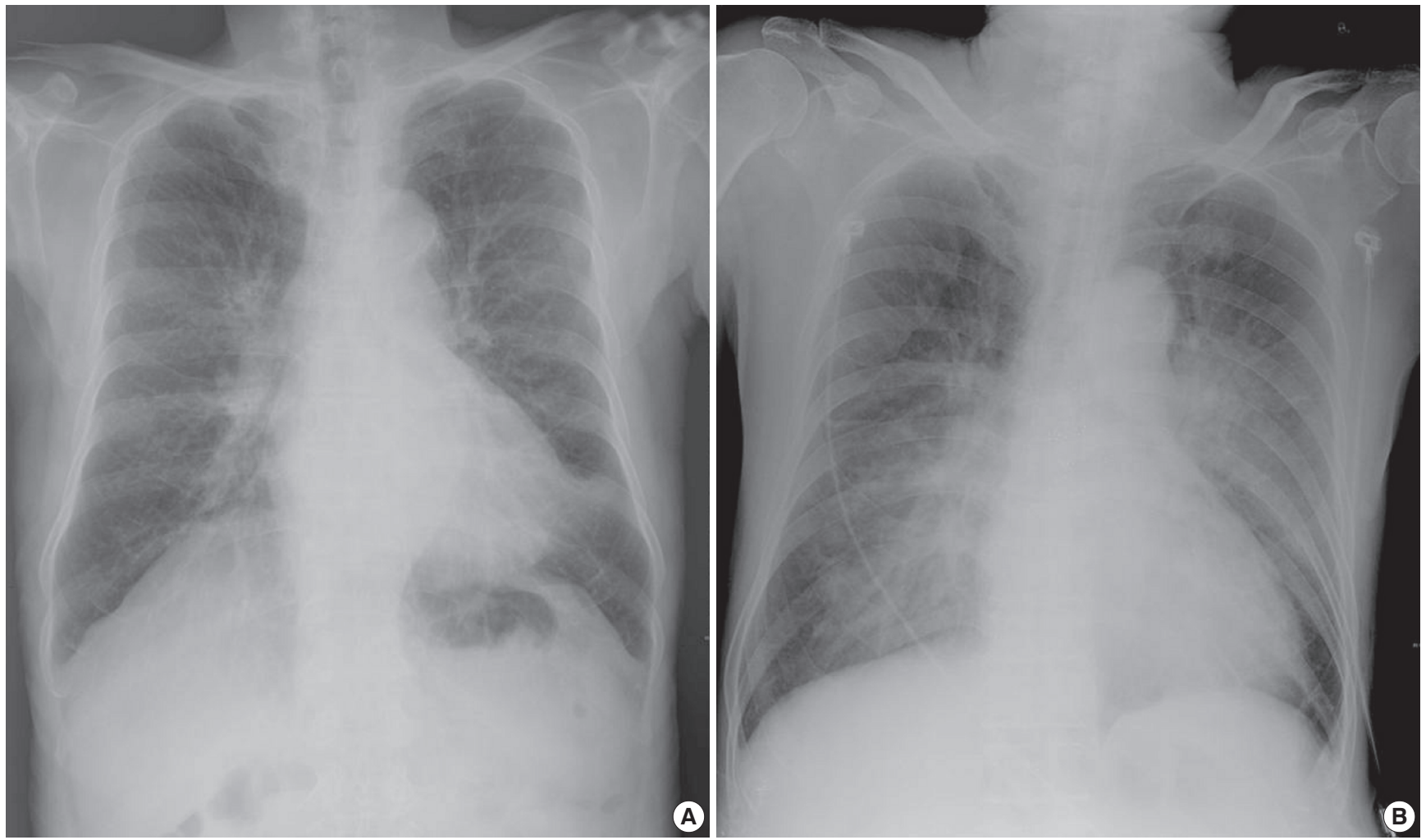

Fig. 1. (A) This showed patch increased opacity in both lungs with increased intersitial marking. (B) This showed increased pulmonary vascularity in both lungs.

were checked immediately and were elevated. (proBNP $8884 \mathrm{pg} /$ $\mathrm{mL}, \mathrm{CK}-\mathrm{MB} 13.8 \mathrm{ng} / \mathrm{mL}$, troponin T $0.56 \mathrm{ng} / \mathrm{mL}$ ) Echocardiography showed the findings compatible with apical ballooning syndrome (hypokinesis or akinesis of the mid and apical segments and sparing of the basal systolic function), with moderately depressed systolic function (ejection fraction [EF] 30\%). Loop diuretic and low dose dobutamine ( $3 \mu \mathrm{g} / \mathrm{kg} / \mathrm{min})$ were administered intravenously. Pulmonary edema was much improved after large amount of urination.

On the fifth day, repeated echocardiography revealed normal wall motion and systolic function (EF 70\%). On the sixth day, cardiac magnetic resonance imaging (MRI) showed no abnormality of the myocardium. On the tenth day, coronary angiography showed no significant stenosis, except focal stenosis of the relatively small distal left circumflex artery. But this lesion was thought not related to this event. Final diagnosis was apical ballooning syndrome followed by pandemic 2009 H1N1 influenza A. On the eleventh day, the patient was discharged without any symptoms and was doing well.

\section{DISCUSSION}

Cardiac complications, including myocarditis, pericarditis and acute myocardial infarction have been rarely associated with seasonal influenza A or B virus infection. It can occur through direct effects of the virus on the myocardium or through exacerbation of pre-existing cardiac disease [2]. The frequency of direct myocardial involvement in influenza infection is variable with rates of up to $10 \%$ [2]. Cardiac MRI may hold promise for the diagnosis of influenza myocarditis and be useful in identification of areas of inflammation in up to $70 \%$ of patients with biopsy-proven myocarditis [3].

Recently, Martin et al. [4] reported that 4.9\% (6/123) of hospitalized pandemic $2009 \mathrm{H} 1 \mathrm{~N} 1$ influenza A had the reversible transient left ventricular dysfunction. Apical ballooning syndrome is a cardiac syndrome characterized by acute ventricular dysfunction in apex of left ventricle, which is known to be reversible and appears to be triggered by a physical or psychological stress in the absence of coronary obstruction [5]. In our case patient, although there was a possibility of myocarditis according to elevated cardiac enzyme and proBNP, and acute left ventricular dysfunction, cardiac 
Park SY, et al. • Apical Ballooning Syndrome in a Patient with Pandemic 2009 H1N1 Influenza A

MRI showed no abnormality on myocardium.

Increased BNP levels were probably associated with hemodynamical stress and correlated with clinical severity and contractility abnormality. BNP levels in the study group of 10 previously healthy patients with apical ballooning syndrome were elevated and negatively correlated with left ventricular ejection fraction [6]. Because cardiac enzymes with proBNP were checked in early period, we could identify the findings compatible with apical ballooning syndrome and treat the heart failure with diuretics and inotropic agent immediately.

The association between influenza and ischemic heart disease is not proven, but the inflammation caused by the influenza virus infection may trigger cardiovascular events like acute myocardial infarction. Though systematic inflammatory markers were used to access the risks, no specific markers were known to be useful to detect apical ballooning syndrome [7].

In hospitalized pandemic $2009 \mathrm{H} 1 \mathrm{~N} 1$ influenza A infection, as well as in seasonal influenza, although the respiratory illness and pneumonia are the main presentation, it might be helpful to measure the proBNP with cardiac enzyme that has been shown to be of high diagnostic accuracy in detecting symptomatic left ventricular dysfunction. In order to predict one of cardiovascular events that might increases mortality risk, the case suggests that proBNP may serve in pandemic $2009 \mathrm{H} 1 \mathrm{~N} 1$ influenza A infection as a early indicator that can identify the ventricular contractility abnormality.

\section{REFERENCES}

1. Thompson WW, Shay DK, Weintraub E, Brammer L, Bridges CB, Cox NJ, et al. Influenza-associated hospitalizations in the United States. JAMA 2004;292:1333-40.

2. Mamas MA, Fraser D, Neyses L. Cardiovascular manifestations associated with influenza virus infection. Int J Cardiol 2008;130:304-9.

3. De Cobelli F, Pieroni M, Esposito A, Chimenti C, Belloni E, Mellone R, et al. Delayed gadolinium-enhanced cardiac magnetic resonance in patients with chronic myocarditis presenting with heart failure or recurrent arrhythmias. J Am Coll Cardiol 2006;47:1649-54.

4. Martin SS, Hollingsworth CL, Norfolk SG, Wolfe CR, Hollingsworth JW. Reversible cardiac dysfunction associated with pandemic 2009 influenza A(H1N1). Chest 2010;137:1195-7.

5. Previtali M, Repetto A, Panigada S, Camporotondo R, Tavazzi L. Left ventricular apical ballooning syndrome: prevalence, clinical characteristics and pathogenetic mechanisms in a European population. Int J Cardiol 2009;134:91-6.

6. Grabowski M, Filipiak KJ, Malek LA, Piatkowski R, Scislo P, Karpinski G, et al. Increased B-type natriuretic peptide levels in patients with apical ballooning syndrome-consecutive cases report. Int J Cardiol 2008;124: 404-6.

7. Warren-Gash C, Smeeth L, Hayward AC. Influenza as a trigger for acute myocardial infarction or death from cardiovascular disease: a systematic review. Lancet Infect Dis 2009;9:601-10. 